\title{
Validation and Verification of Temporal Knowledge as an Important Aspect of Implementing a Temporal Knowledge Base System Supporting Organizational Creativity
}

\author{
Maria Mach-Król \\ University of Economics \\ ul. Bogucicka 3, 40-226 Katowice, \\ Poland \\ Email: maria.mach- \\ krol@ue.katowice.pl
}

\author{
Krzysztof Michalik \\ University of Economics \\ ul. Bogucicka 3, 40-226 Katowice, \\ Poland \\ Email:krzysztof.michalik@ue.kato \\ wice.pl
}

\begin{abstract}
The paper is devoted to the problem of temporal knowledge validation and verification during the process of implementing a system supporting organizational creativity. The motivation for implementing a temporal knowledge base system is presented, the implementation methodology is outlined, and the $V \& V$ (validation\&verification) process is described in detail, using an example of the Logos reasoning tool. The main achievements of the paper are: elaborating a new implementation methodology for a temporal knowledge base system, and elaborating detailed V\&V steps.
\end{abstract}

Keywords: organizational creativity, temporal knowledge base system, validation, verification, implementation methodology, Logos tool.

\section{INTRODUCTION}

O RGANIZATIONAL creativity is a relatively new concept in the theory of management, which has partially arisen on the ground of knowledge management. There are many definitions of organizational creativity, but it is commonly perceived as a team, dynamic activity, responding to changing features of organization's environment, a team process - see e.g.[15], [1].

The organizational creativity is therefore to be perceived in the context of organizational dynamics, because it depends on the situational changes and is composed of processes. Therefore while discussing the question of computer support for organizational creativity, the temporal aspects should not be omitted.

Such a way of formulating this problem - underlining its dynamic aspect - justifies a proposal of using an intelligent system with a temporal knowledge base, as a tool supporting creation and development of organizational creativity, which is understood as organizational asset (see e.g. [7], [14]).

By the system with a temporal knowledge base we will understand (slightly modifying the definition given in [8]) an artificial intelligence system, which explicitly performs temporal reasoning. Such a system contains not only fact base, rule base, and inference engine, but also directly addresses the question of time. For an intelligent system to be temporal, it should contain explicit time representations in its knowledge base - formalized by the means of temporal logics - and at least in the representation and reasoning layers. In the paper we use an example of the Logos tool - a reasoning system constructed by the authors within the frame of the research project under the same name. One of the assumptions of the Logos project is the possibility of using it for different scientific researches and experiments, among others using it for building temporal knowledge base research prototype.

The main aim of the paper is to present a new implementation methodology for a temporal knowledge base system supporting organizational creativity, and to present - in detail - the steps performed during validation and verification of the temporal knowledge embedded in the system.

\section{MOTIVATION}

While reading many authors' discussions on the essence of organizational creativity, one sees that this is primarily team activity. The effect of this activity may be referred to as "creative knowledge", which itself generates new ideas, concepts, and solutions. To do so, the creative knowledge must be first codified, and next disseminated. This justifies the use of a knowledge base system. But the creative knowledge changes in time, due to several reasons.

First, organizational creativity is a process, therefore its effects are subject to change. Moreover, the process encompasses solving problems that also change, because the organization's environment changes [8] p. 13-15, [3] p. 150 and next, 176 and next.

Second, each knowledge - including the creative one changes simply with the passage of time, with the flow of new information about objects [2].

Third, organizational creativity is linked with dynamics, which can be seen e.g. in the assets approach to this creativity 
or in the requirement of adapting creative knowledge to situational context.

All the above leads to conclusion that a knowledge base system is not enough to support organizational creativity, because classical knowledge bases do not support time. Therefore in this paper we propose the use of a temporal knowledge base system, as defined earlier. Such system is able to perform the tasks arising from the characteristics of organizational creativity and its artifacts.

An important element of the implementation methodology of the proposed system is the process of validation and verification of temporal knowledge embedded in the system. The system is a rule-based one (strictly speaking: a temporal rule-based one), thus in order to run properly, its knowledge base must be correct. And a "correct" temporal knowledge base means that it has been verified and validated to ensure that there are no anomalies such as: redundant rules, subsuming rules, contradictory rules, unused attributes, unused values, recursive rules (inference loop, circularity),

Thus, the procedures of validation and verification $(\mathrm{V} \& \mathrm{~V})$ are an important fragment of implementation methodology for the proposed system. In more detailed manner we describe this problem in section 5 .

\section{RELATED WORK}

In the literature, there are many methodologies concerning expert systems, among others [9], p. 136:

- blackboard architecture,

- KADS and CommonKADS,

- HyM for hybrid systems,

- Protégé,

- CAKE.

It must be however noted, that the above mentioned methodologies have been created for expert system, while the proposed temporal knowledge base system is not a typical ES. In the context of its architecture, it is worthy of considering the blackboard architecture, which is by some authors understood as a knowledge engineering methodology [6]. It enables to explicitly represent knowledge and its structure in a rule-based system (and the proposed temporal knowledge base system is a rule-based one). It may be acknowledged that a postulated division of system's knowledge base into several sub-bases means implementing the blackboard architecture and achieving its assumptions.

The second interesting methodology is CAKE (Computer Aided Knowledge Engineering), elaborated by Michalik. The detailed description of CAKE may be found e.g. in [11], [9]. Its advantages are similar to those of the blackboard methodology:

- use of the blackboard systems methodology,

- easy management of heterogeneous knowledge sources,

- $\quad$ support of groupworking,
- $\quad$ automatic control of formalized creative knowledge code,

- knowledge base editor,

- a package of wizards facilitating the coding process of the acquired knowledge.

It has to be pointed out, however, that the knowledge coding formalism, embedded in the CAKE system, has no temporal references. A sample diagram of knowledge base anomalies can be found e.g. in [16] and more detailed discussion on verification and validation in [12]. Some introductory concepts concerning $\mathrm{V} \& \mathrm{~V}$ in Logos system being subject of our presentation can be found in [10]. Very interesting remarks on $\mathrm{V} \& \mathrm{~V}$ in the context of knowledge engineering in the CommonKADS Methodology can be found in [13]. Authors differentiate between internal validation for both internal and external meaning, e.g. saying that some people use the term verification for internal validation and apply validation concept against user requirements ("is it the model right?").

\section{SySTEM IMPLEMENTATION METHODOLOGY}

It is also important that the aforementioned methodologies relate mainly to building expert systems, while the methodology needed for a temporal knowledge base system has to take into account also the processes of implementing the system in a creative organization. Therefore it is not possible to directly use any of the aforementioned methodologies, and a new one has to be developed, suited to the task of supporting organizational creativity by a temporal knowledge base system. Two very important questions thus arise.

First, the proposed system is an intelligent one, containing at least one temporal knowledge base, therefore the implementation methodology has to make use of (but not copying directly) existing methodologies for implementing such systems, as e.g. expert ones.

Second, the main aim of the system is to support organizational creativity, therefore the most important system elements are user interface and knowledge base. The first enables both adding creative knowledge to the system, and querying this kind of knowledge, the second is needed in representation and reasoning layers. The proposed methodology should accommodate also these elements.

The implementation methodology for a temporal knowledge base system has to be conformable to temporal knowledge base system's lifecycle. We propose the following lifecycle for the system (adapted from [5]):

1. Problem identification, and definition of users' needs;

2. System's formal specification, encompassing dialogues with users;

3. Definition of knowledge sub-bases', and general knowledge base structure and scope, choice of knowledge representation technique(s), creation of reasoning algorithm;

4. Creative knowledge acquisition;

5. Prototype creation and verification;

6. System coding and testing; 


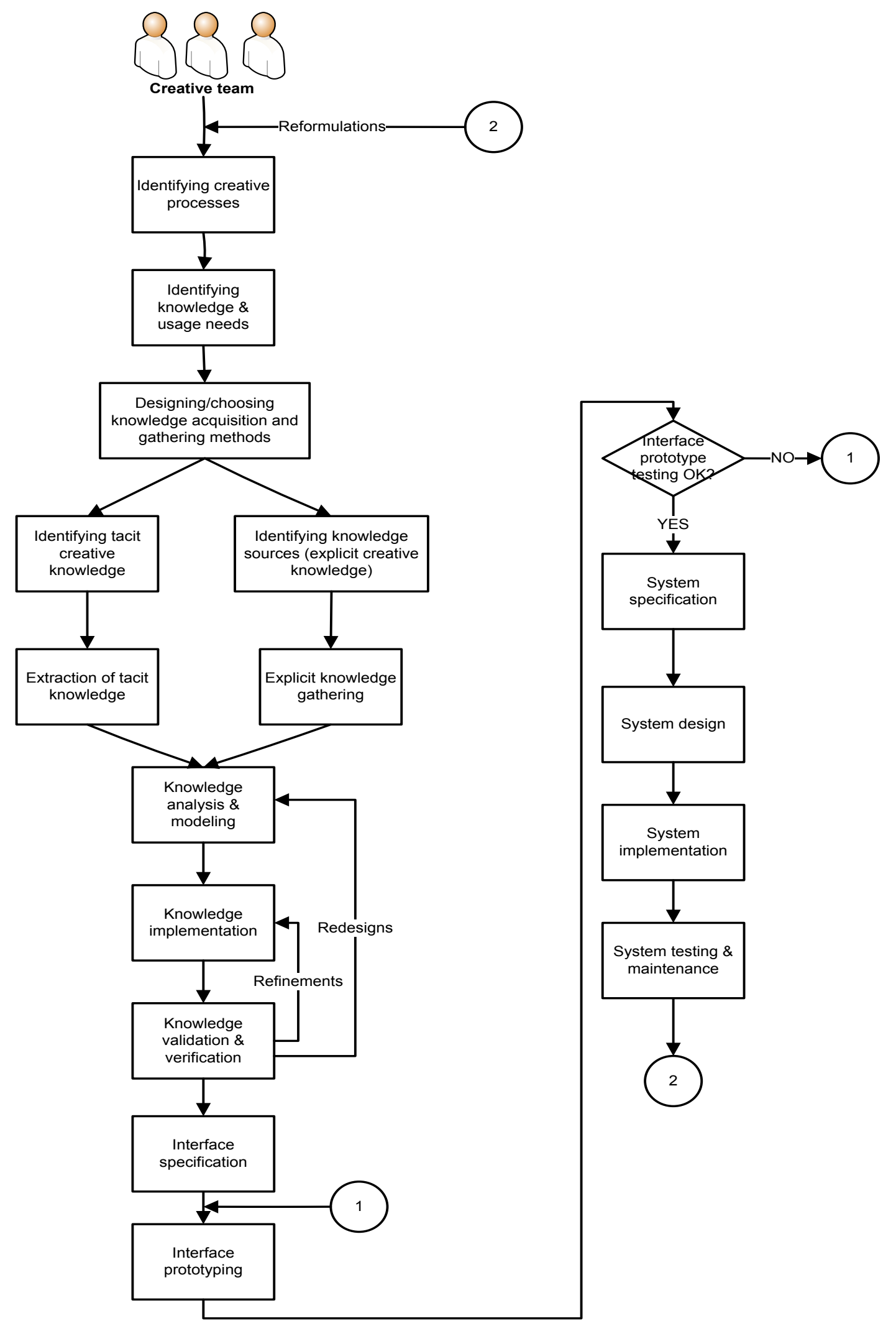

Fig. 1. Schema of temporal knowledge base system implementation methodology

Source: Own elaboration. 
7. System maintaining and development - principally the creative knowledge bases and user interface.

The implementation methodology for the temporal knowledge base system covers points 1,2, 4-6, and 7 of the proposed system's lifecycle.

The methodology should be focused primarily on the creative knowledge, and on user interface. Therefore its main elements are creative knowledge engineering, and system engineering, with emphasis put on interface design and prototyping. The general structure of the proposed methodology is presented in fig. 1.

The proposed methodology has been inspired by other knowledge engineering methodologies for the process of knowledge management - particularly by the work [18] - and by classical, fundamental methodologies for implementing expert systems: [17], p. 135-139, and [4], p. 139. Obviously, it was not possible to directly merge the existing models, the proposal concerning knowledge engineering had to be remodeled in the context of organizational creativity process, while methodologies for implementing expert systems had to be adapted to the temporal knowledge base system, and its main task.

The methodology for implementing a temporal knowledge base system starts with the group of activities concerning capturing, and modeling of creative knowledge. At this stage it is essential to discover creative processes running within the team of employees involved in organizational creativity. This will enable to identify needs concerning the creative knowledge, and its usage by an organization (or team). Having this information, the next step of the methodology is to choose and/or design tacit creative knowledge acquisition methods, as well as to acquire explicit creative knowledge. This is so because we assume that the creative knowledge, as any other kind of knowledge, may be divided into tacit and explicit one. Next, it is necessary to identify (with the aid of previously gathered information) tacit knowledge, and sources of explicit knowledge, and to acquire both types of creative knowledge. Only then it is possible to model and analyze the creative knowledge, which is to be incorporated in the temporal knowledge base system.

During each stage of the proposed methodology, especially during the creative knowledge engineering stage, it is indispensable to closely cooperate with system users, that is the employees involved in the process of organizational creativity. Without them it is impossible to identify, and to acquire tacit knowledge. Moreover, the system will be useful only if people want to use it.

Activities concerning creative knowledge modeling, implementation, and verification are absolutely crucial, therefore in the proposed methodology there is a possibility to return to previous stages, in order to refine knowledge representation and implementation, or even to completely change the design of the knowledge model.

It also has to be explained why activities concerning system's specification, design, and implementation are placed at the end of the methodology, which differs from classical implementation methodologies for intelligent systems. As it has been already said, the main task for the temporal knowledge base system is to support organizational creativity, so its most essential elements are temporal creative knowledge base(s) and GUI. Thus the methodology is focused on these elements. Activities concerning system's engineering are also important, but are of ancillary nature regarding temporal $\mathrm{KB}$, creative knowledge management, and GUI design.

As it has been already said, an important element (step) in the proposed methodology concerns temporal knowledge validation and verification, to ensure that the knowledge base is correct. The V\&V step is preceded by knowledge analysis\&modeling, and knowledge implementation. These three steps may be followed several times, continuously refining the knowledge base. Due to the importance of the $\mathrm{V} \& \mathrm{~V}$ procedure, it is described in detail in the next section.

\section{V.VALIDATION AND VERIFICATION OF TEMPORAL KNOWLEDGE DURING THE PROCESS OF IMPLEMENTING A TEMPORAL KNOWLEDGE BASE SYSTEM - THE LOGOS} EXAMPLE

As mentioned, we build the Logos reasoning system, being software platform for our experiments with temporal knowledge bases as well as with temporal reasoning. Additionally, while developing this system, we take into account the very important factor of $\mathrm{V} \& \mathrm{~V}$. At present main procedures discovering some anomalies in knowledge bases are ready. What have to be done - according to our thesis concerning V\&V in temporal knowledge bases - is creating algorithms to discover some specific temporal anomalies. The thesis is that in temporal knowledge bases some new, very specific anomalies and errors, may theoretically appear. On the other hand, most of $\mathrm{V} \& \mathrm{~V}$ methods already built-in in Logos for conventional (not temporal) knowledge bases are also useful and even necessary. The reason is that temporal knowledge bases may include the same kind of anomalies as the conventional ones. Most of the temporal anomalies we plan to detect as a first step while building Logos relate to incorrect time dependencies as declared in knowledge base. As we mentioned in section 3, the correct temporal knowledge base means that it has been verified and validated to ensure that there are no anomalies such as the following [11], [9]:

\section{Redundancy}

Two rules we regard as redundant, if for two rules:

$\mathrm{R}_{\mathrm{i}} \leftarrow \mathrm{W}_{\mathrm{i} 1 \wedge . . \wedge \mathrm{W}_{\text {in }} \text { and }}$

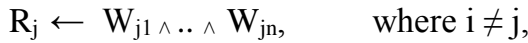

holds: $\left\{\mathrm{W}_{\mathrm{i} 1} . . \mathrm{W}_{\mathrm{in}}\right\}=\left\{\mathrm{W}_{\mathrm{j} 1} . . \mathrm{W}_{\mathrm{jn}}\right\}$

\section{Subsuming rules}

If for two different rules:

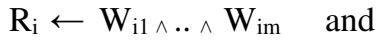

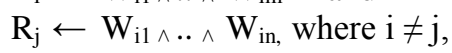

holds $\left\{\mathrm{W}_{\mathrm{i} 1}, . ., \mathrm{W}_{\mathrm{im}}\right\} \subseteq\left\{\mathrm{W}_{\mathrm{i} 1}, . ., \mathrm{W}_{\text {in }}\right\}$, then we say, that rule $R_{j}$ subsumes $R_{j}$.

\section{Contradictory rules}

Two rules we regard as contradictory if

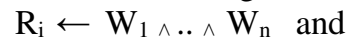


$\neg \mathrm{R}_{\mathrm{j}} \leftarrow \mathrm{W}_{1 \wedge . . \wedge} \mathrm{W}_{\mathrm{n}}, \quad$ where $\mathrm{i} \neq \mathrm{j}$.

\section{Inconsistent rules}

Two rules we regard as inconsistent if

$\mathrm{R}_{\mathrm{i}} \leftarrow \mathrm{W}_{1} \wedge . . \wedge \mathrm{W}_{\mathrm{n}}$ and

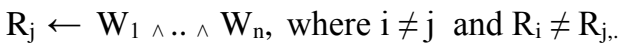

In our opinion, in such case system should give warning for knowledge engineer about possibility of inconsistency as understood in logic (here we use terminology of our system). Such situation, may in fact potentially lead to a contradiction or can be result of any other mistake of knowledge engineers they should be aware.

\section{Incompleteness}

We assumed that temporal knowledge base is complete when contains all possible combinations of attributes and their allowable values in rules' antecedents and consequents. It should be noticed that in practice not all combinations are required, so this kind of verification is only warning for knowledge engineer that some rules could be missing.

\section{Missing rules}

The anomaly called here as missing rules can be treated as a special case of incompleteness. While creating V\&V module of Logos system we consider missing rules as the case when some of decision-making attributes are not present in any of the rule antecedents. This situation can appear as side effect of rapid prototyping and incremental method of knowledge base development.

\section{Unused attributes and values}

Our system in order to be able to detect some anomalies and errors requires explicit declaration of attributes and values being used in the knowledge base. When given attribute or value is never used in any of rules then Logos gives warning addressed to knowledge engineer because it may be information about serious anomaly in knowledge base. On the other hand, similarly as in the case of missing rules it can be side effect of using methodology of rapid prototyping and incremental development of knowledge base.

\section{Recursive rules (inference loop, circularity)}

Recursion in most of rule-based systems is very important anomaly in knowledge base with serious consequences and sometimes very difficult to detect by knowledge engineer without software support, e.g. as implemented in our Logos system. Recursion in this context may take a variety of patterns. In the simplest case can be like this:

$$
\mathrm{K}_{\mathrm{i}} \leftarrow \mathrm{W}_{1} \text { and } \mathrm{K}_{\mathrm{i}}=\mathrm{W}_{1}
$$

This type of recursion (loop) is very easy to detect for knowledge engineer, even without special algorithms. The sign ' $=$ ' does not mean simple equality but may have more complex semantics of ability of two expressions to match. Other variants of the same direct recursive call of the conditions to the conclusions of the rule may take one of the following schemes:

$$
\begin{aligned}
& \mathrm{K}_{\mathrm{i}} \leftarrow \mathrm{W}_{1} \wedge . . \wedge \mathrm{W}_{\mathrm{n}} \text { and } \mathrm{K}_{\mathrm{i}}=\mathrm{W}_{1} \\
& \mathrm{~K}_{\mathrm{i}} \leftarrow \mathrm{W}_{1} \wedge . . \wedge \mathrm{W}_{\mathrm{n}} \text { and } \mathrm{K}_{\mathrm{i}}=\mathrm{W}_{\mathrm{n}} \\
& \mathrm{K}_{\mathrm{i}} \leftarrow \mathrm{W}_{1} \wedge . . \mathrm{W}_{\mathrm{j} . .} \wedge \mathrm{W}_{\mathrm{n}} \text { and } \mathrm{K}_{\mathrm{i}}=\mathrm{W}_{\mathrm{j}}
\end{aligned}
$$

While recursion in rules of logic programs is very useful and correct situation (provided their correct semantics), the recursion in expert systems is generally treated (as mentioned) as serious knowledge base anomaly.

We rejected using recursions in Logos for many reason, the main is that logic programming is first of all programming formalism (e.g. Prolog) and not knowledge representation language for temporal knowledge bases.

Much more difficult situation to detect by the knowledge engineer is that of indirect recursion. Sometimes, in large knowledge bases with several levels of inference, it can be practically not possible to detect in reasonable time. Then software support as e.g. that we implemented in Logos is absolutely necessary. In such case of indirect recursive call it does not occur at the same level of a given rule to its conclusion, within a single rule. This can be illustrated by the following example:

$$
\begin{aligned}
& \mathrm{R}_{1}: \mathrm{K}_{1} \leftarrow \mathrm{W}_{11} \wedge . . \mathrm{W}_{1 \mathrm{j}} . . \wedge \mathrm{W}_{1 \mathrm{x}} \\
& \mathrm{R}_{\mathrm{i}}: \mathrm{K}_{\mathrm{i}} \leftarrow \mathrm{W}_{\mathrm{i} 1} \wedge . . \mathrm{W}_{\mathrm{il}} . . \wedge \mathrm{W}_{\mathrm{iy}} \\
& \mathrm{R}_{\mathrm{n}}: \mathrm{K}_{\mathrm{n}} \leftarrow \mathrm{W}_{\mathrm{n} 1} \wedge . . \mathrm{W}_{\mathrm{nm}} . . \wedge \mathrm{W}_{\mathrm{nz}} \\
& \text { where: } \mathrm{W}_{1 \mathrm{j}}=\mathrm{K}_{\mathrm{i}} \mathrm{i} \mathrm{W}_{\mathrm{il}}=\mathrm{K}_{\mathrm{n} .} \mathrm{i} \mathrm{W}_{\mathrm{nm}}=\mathrm{K}_{1} \text { and '=' means } \\
& \text { matching/unification }
\end{aligned}
$$

In this case, the recursive call is related to a lower level in the hierarchy of rules, making its location is difficult to detect for a knowledge engineer. NB: Incidentally, defined earlier contradiction of rules - as mentioned - can also be caused by indirect inference.

Direct contradiction:

$\mathrm{p} \leftarrow \mathrm{q}$

$\neg \mathrm{p} \leftarrow \mathrm{q}$.

Indirect contradiction appearing during inference process:

$$
\begin{aligned}
& \neg \mathrm{p} \leftarrow \mathrm{r} \\
& \mathrm{p} \leftarrow \mathrm{q} \\
& \mathrm{q} \leftarrow \mathrm{r} .
\end{aligned}
$$

\section{CONCLUDING REMARKS}

Our main goal at this stage of research was design and development of software platform to make experiments with temporal knowledge bases. In this paper we focused on the problem on $\mathrm{V} \& \mathrm{~V}$, which is always present while building knowledge bases, but sometimes underestimated. The 
consequences of badly evaluated knowledge bases in this respect can be very serious, and for example some anomalies can't be detected for long time giving bad decisions. The more so, as we showed some of the anomalies, as for example recursions (inference loops) can be sometimes very difficult to detect by knowledge engineer. So our objective since the beginning of the project Sphinx was to build computer aided knowledge engineering system automatically supporting knowledge engineer especially helpful in such difficult to analyze cases. The next step in our researches concerning temporal knowledge bases will be identification of the specialized anomalies typical only for temporal systems. We suspect that beside the simple related to time errors we may discover special kind of temporal anomalies. Even some of already identified and described in our paper some anomalies can take the new character in relation to time. We have also additional hypothesis that temporal knowledge bases have kind of anomalies which are completely specific and different from that described. Verification of theses hypothesis we take as our next goal of our researches.

\section{REFERENCES}

[1] Andriopoulos, C. and Dawson, P., 2014. Managing Change, Creativity and Innovation. Second Edition. Los Angeles/London/New Delhi/Singapore/Washington DC: SAGE Publications.

[2] Benthem van, J., 1995. Temporal Logic. In: D. M. Gabbay, C. J. Hogger and J. A. Robinson, Eds. Handbook of Logic in Artificial Intelligence and Logic Programming. Volume 4: Epistemic and Temporal Reasoning. Oxford: Clarendon Press, pp. 241-350.

[3] Czaja, S., 2011. Czas w ekonomii. Sposoby interpretacji czasu $w$ teorii ekonomii $i$ w praktyce gospodarczej. Wrocław: Wydawnictwo Uniwersytetu Ekonomicznego.

[4] Hayes-Roth, F., Waterman, D. and Lenat, D. Eds., 1983. Building Expert Systems. Reading, Mass.: Addison-Wesley Publishing Company.
[5] Infernetica, 2012. Systemy ekspertowe dla biznesu. [Online] Available at: http://infernetica.com/systemy-ekspertowe/ [Accessed: 0704 2014].

[6] Kendal, S. and Creen, M., 2007. An Introduction to Knowledge Engineering. London: Springer.

[7] Krupski, R., Ed., 2011. Rozwój szkoty zasobowej zarzqdzania strategicznego. Wałbrzych: Wałbrz.Wyż.Szk.Zarz. i Przedsięb.

[8] Mach, M. A., 2007. Temporalna analiza otoczenia przedsiębiorstwa. Techniki i narzędzia inteligentne. Wrocław: Wydawnictwo AE.

[9] Michalik, K., 2014. Systemy ekspertowe we wspomaganiu procesów zarzadzania wiedza $w$ organizacji. Katowice: Wydawnictwo Uniwersytetu Ekonomicznego.

[10] Michalik, K., 2015. Validation and .Verification of Knowledge Bases in the Context of Knowledge Management. Logos Reasoning System Case Study, [w:] Technologie wiedzy w zarządzaniu publicznym'13, red. J. Gołuchowski, A. Frączkiewicz-Wronka, Wydawnictwo UE, Katowice (in print)

[11] Michalik, K., Kwiatkowska, M. and Kielan, K., 2013. Application of Knowledge-Engineering Methods in Medical Knowledge Management. In: R. Seising and M. E. Tabacchi, Eds. Fuzziness and Medicine: Philosophical Reflections and Application Systems in Health Care. Berlin Heidelberg: Springer, pp. 205-214.

[12] Owoc M., Ochmańska M., Gładysz T., 1999. On Principles of Knowledge Validation, [in:] Validation and Verification of Knowledge Based Systems: Theory, Tools and Practice, eds. A. Vermessan, F. Coenen, Kluwer Academic Publishers, Boston.

[13] Schreiber et al., 2000. Knowledge Engineering and Management, The CommonKADS Methodology, The MIT Press, Cambridge MA,.

[14] Sirmon, D. G., Hitt, M. A., Ireland, R. D. and Gilbert, B. A., 2011. Resource Orchestration to Create Competitive Advantage: Breadth, Depth, and Life Cycle Effects. Journal of Management, September, Vol. 37 (No. 5), pp. 1390-1412.

[15] Unsworth, K. L., 2001. Unpacking Creativity. Academy of Management Review, Vol. 26(No. 2), pp. 286-297.

[16] Vermessan A.I., 1998. Foundation and Application of Expert System Verification and Validation, [in:] The Handbook of Applied Expert Systems, ed. J. Liebowitz, CRC Press, New York 1998.

[17] Waterman, D., 1986. A Guide to Expert Systems. Reading, Mass.: Addison-Wesley Publishing Company.

[18] Yazdanpanah, A. and Sadri, R., 2010. Proposed Model for Implementation Expert System for the Planning of Strategic Construction Projects as a Tool for Knowledge Management. Istanbul, IPMA. 